\title{
The Blended Librarian and the Disruptive Technological Innovation in the Digital World
}

\author{
Georgina Araceli Torres Vargas, Egbert J. Sánchez Vanderkast, \\ Ariel Alejandro Rodríguez García, Jenny Teresita Guerra González
}

Institute for Library and Information Studies, National Autonomous University of Mexico, Mexico City, Mexico

Email: gatv@unam.mx

Received 20 July 2015; accepted 10 August 2015; published 13 August 2015

Copyright (C) 2015 by authors and OALib.

This work is licensed under the Creative Commons Attribution International License (CC BY). http://creativecommons.org/licenses/by/4.0/

(c) (7) Open Access

\section{Abstract}

In the librarianship literature, blended librarians are integral professionals with the theoretical knowledge of Library and Information Science and simultaneous competences allowing them to deal with printed and digital information; they also have the knowledge on the use and management of information and communication technologies (ICTs). Considering the aforementioned, this paper debates: 1) the ideas of innovation and technological innovation models; 2) the disruptive technological innovation and its connection with the current library and information science scenario; and 3) the blended librarian and its challenges in the information systematization for access, retrieval and information services in a digital world context.

\section{Keywords}

Blended Librarian, Disruptive Technological Innovation, Information Retrieval, Information Systematization, Digital Information Services

\section{Subject Areas: Information Science}

\section{Introduction}

Technological innovations generate constant changes and challenges in the information environment. In daily practice, the blended librarian must adapt to those phenomena.

The continuous emergence of new means of educational communication makes libraries and librarians redesign learning common spaces and areas in order to attract more users. They are experiencing a transition of forms and formats in which user access, store, recover and use of information, once basically printed, is abun-

How to cite this paper: Vargas, G.A.T., Vanderkast, E.J.S., García, A.A.R. and González, J.T.G. (2015) The Blended Librarian and the Disruptive Technological Innovation in the Digital World. Open Access Library Journal, 2: e1764.

http://dx.doi.org/10.4236/oalib.1101764 
dantly digital today. The traditional roles of libraries and librarians are altered and reinvented in front of the horizon of possibilities and challenges brought by the Internet, changes in the web and digital contents which are continuously emerging.

In daily practice, the blended librarian must adapt to those phenomena in order to achieve an adequate organization of the information that facilitates its access and retrieval.

\section{Technological Innovation: Three Models to Understand It}

Joseph Alois Schumpeter, an Austrian-American economist, defined innovation as "the introduction of new products and services, new processes, new supply sources and changes in the industrial organization, in a continuous way and addressed to the client, consumer or user”.

Specifically, technological innovation refers to the transformation of ideas in new and useful products and/or processes, as well as a significant technological improvement of those that already exist. Prior to 1960s, the related subjects were not relevant. In that time, a theoretical trend arose pointing out to the innovation as an essential element in the prosperity of the developed countries and technology as the main factor of innovation. Technological innovation becomes the vital ingredient to support prosperity, making huge investments in research and development $(\mathrm{R}+\mathrm{D})$ in developed countries.

Over time, three theoretical/explanatory models of technological innovation were clearly distinguishable. They are described below:

1) Technological determination: This first model identifies the scientific and technological advances as the determining factors of inventive activity and technological innovation. It states that there is no dependency between the innovative practice and economic factors. Its use is restricted to explain certain radical innovations in which the market demand seems to have little influence.

2) Technological innovation from the market demand perspective: This model states that necessity is the cause of innovation. Necessities are military, civil or social, translating in an intensification of the technological efforts to cover these. The model suspects that necessity assumes the capacity of acquisition and thus, of demand.

Despite the model is supported on the possibility of knowing the direction where the world is going to, it presents various deficiencies trying to explain how the necessities and demands can be known on inexistent goods. Assuming that innovation depends only on the market, forces the ratification that technology is viable to aim for whatever is wanted at any time.

3) Integral conception of the innovation process: The last model is more complex by considering the interaction between science, technology and market as a constant activity permanently changing. It affirms innovation is not spontaneous, but requires a hard effort of creation, development, test and introduction in the economic life. In this sense, innovation will be a suitable articulation between the detected necessity and the technical possibility to satisfy it [1].

Considering the third model as a path, we have to point out that the potentiality to innovate in the technological field needs to take consider two issues: the areas of internal and external change of the socio-economic sector, institution or company. Internal change areas include competence analysis; sector, institution or company analysis; users' and clients' expectations analysis, and analysis of processes used in the sector. External change areas include demographic, socio-cultural and scientific-technological factors.

In the library sector, internal change areas are those addressed to the knowledge that these professionals obtain through their formal education. External change areas comprise the demand of knowledge, skills and abilities that the Library and Information Science professional has to acquire in his/her professional practice. We refer particularly to the knowledge obtained in the context of constant innovation of ICTs.

\section{The Disruptive Technological Innovation and Its Repercussion in the Role of the Library and Information Science Professional}

As explained previously, technological innovation-mostly linked to the business sector-has been usually associated with gradual transformations in the means of production. On the contrary, the disruptive technological innovation involves an abrupt rupture in the technological system generating the disappearance of products or services used up until that time by society.

This peculiar type of innovation leads to the introduction or modification of organizational structures, distri- 
bution of roles and internal and external responsibilities. It involves to set out strategic orientations that influence the organization [2]. The library of the University of Texas, Southwestern, is an example. In 2003, after incorporating resources and digital services, it increased the staff workload and responsibilities. This modified their routines demanding other type of knowledge, including website design. The team members found that is was more and more difficult to determine priorities of the multiple departments, along with a concern for the poor performance of some librarians [3].

The continuous emergence of new means of educational communication makes libraries and librarians redesign learning common spaces and areas in order to attract more users. They are experiencing a transition of forms and formats in which user access, store, recover and use of information, once basically printed, is abundantly digital today. The traditional roles of libraries and librarians are altered and reinvented in front of the horizon of possibilities and challenges brought by the Internet, changes in the web and digital contents which are continuously emerging.

In this context, Brower [4] mentions that Library and Information Science is surrounded by a vast mixture of theoretical traditions where those previous are lost or diluted among those recently acquired. Immersed in the disruptive technological innovation, libraries and librarians create a complex work and communicative relationship that makes them blend practices distinctive of the discipline with those from other areas of knowledge that complement and broaden their professional horizons.

Although there are people in favor of the very rapid change imposed by innovation, there are also others considering libraries and librarians must not evolve so fast.

In the second decade of the $21^{\text {st }}$ century, one might ask: is there a term to define current libraries and librarians? During the first fifteen years of this century, a number of proposals centered around technological innovation and disruptive technological innovation. All of these are based on the idea that libraries have an administration system and participate in the dissemination and use of knowledge, inferring that librarians are professionals constantly changing and adapting to the complicated environment of digital information and ICTs.

The new roles played by librarians, supported by ideas similar to innovation, derived in the introduction of metaphors such as "feral professionals" (2006), which defined employees of libraries not requiring a degree in Library Science to work in such entities. Another case is the Council on Library and Information Resource, which coined "hybrid librarian" for the professional that, along to performing traditional functions in the information units, also coordinates or belongs to work groups. His/her versatility will facilitate the design of new models of teaching, digital education and development of special collections.

\section{The Blended Librarian (BL) and His/Her Role in the Organization, Information Retrieval, and Information Services}

Recently, and in agreement with the disruptive technological innovation, Bell and Shank [5] proposed the term blended librarian, a metaphor describing librarians involved in the learning process where they display technological management skills. The library is now an automated center in which the new librarian provides guidelines for a better use of technological innovations by the users (basis of the system). However, in order to achieve this, it will be necessary to articulate the theoretical knowledge that supports a profession, with those favored by technological innovation.

The library image is continuously transformed since the appearance of ICTs. At the beginning, there was the traditional or conventional library, where collections and bibliographic control had paper as the technological substrate. These very rapid advances make us alternate from one image of the library to another due to the fact that the dominant model is modified. The Library 2.0 model that uses the Web 2.0 potentialities is a clear example.

Now the semantic library reflects the tendencies in the management of information based on Web 3.0. Ryszard [6] states that semantic digital library is the next generation of digital library recognizable because it:

- Integrates information of different types of metadata.

- Offers interoperability with other systems (not only between digital libraries) at a metadata communication level.

- Allows a robust search based on semantic resources.

The disruptive technological innovation produces changes in the concept of library and in the work of the Library and Information Science professional, which leads to consider him/her as a disruptive librarian, that is, the 
professional that adapts very rapidly to technological demands.

Bell and Shank use the category of blended librarian referring to the professional that combines traditional abilities of Library and Information Science with skills from information technologies and computer science. Although authors focus their attention in the Library and Information Science professional role in users' formation for the management of ICTs, they list some key features, which can provide an idea about the new specialist:

1) Leadership. Leadership is an innovative attribute of Library and Information Science professionals as agents of change; key in information delivery services for the contemporary society.

2) Collaborator. Collaborates actively in the technological instructional dialogue: develops programs, services and resources that facilitate the educational mission of the academic library.

3) Proactive. The attributes of collaboration, creativity and adaptability guarantee that the blended librarian be a proactive professional in continuous communication and collaboration with the new actors of the technological area.

4) Transformer. The relationships with community members must be modified to make viable efforts for the integration of technology and library resources.

The above mentioned statements study conducted by Nielsen [7], indicated that blended librarians need to broaden their knowledge on technologies and acquire the skills to use e-books and e-journals; creation of databases; management of social networks for collaboration and communication, as well as knowledge for video production. The study takes a close look into the skills and abilities blended librarians must have.

Likewise, these professionals need to face more specialized issues, for example, instruments for the design of information architecture and information retrieval systems; generation of new products (ontologies, taxonomies, data mining, text mining). The thin line distinguishing the disruptive librarian from the blended librarian is that the first frequently leaves his/her usual functions to perform new ones, while the second integrates new knowledge to the previous one.

Disruptive technological innovation is an element that stimulates the formation of a new generation of professionals capable to perceive opportunities in the current emergent information models. However, it is important to continue with the formation of specialists with a solid theoretical background allowing them to develop new proposals for offering optimal information products and services. If there is only technological knowledge, a possible risk exists of just having momentary solutions driven by the uses imposed by technology and its innovations, lacking of alternatives that allow their continuous redirection and improvement. Currently, in the case of information organization, there is a new interest in the scenario of the blended librarian in which his/her alternatives and activities are essential.

\subsection{The BL in the Information Organization}

The processes in the bibliographic control, have been an obstacle in the development of librarian systems since its technological advances maintain its support on the paper industry. The migration from the electronic to the digital environment still is a great challenge that requires a significant technological substitution.

The assertions of Lewis reinforce the aforementioned by clarifying that in the last 25 years librarians ignored searches using algorithms. By extrapolating this phenomenon, it is understandable that Web needs do not follow the cataloguing practices implemented in library activity. However, how does the information and knowledge organization react in front of the disruptive technological innovation? This particular condition of innovation has come as a revitalizing resource of the organizational culture, modifying work processes and methods, provoking evident and hidden metamorphoses.

Hidden transformations are difficult to identify because these influence in the new librarian responsibilities. These are associated with the acceptance of technology: new models, processes and techniques capable to improve performance.

Christensen [8] proposes some influent economic-administrative theses within the conceptual perspective used in this presentation, since the innovating dilemma requires us to add practices and principles from other disciplines.

Companies (libraries) depend on their clients (users) and investments on their resources (collections). The library administration recognizes that the incorporation of new technology requires a huge investment. The existing one will hardly support the storage and use of information resources requested by institutions and users. 
Small markets do not resolve the growing needs of big companies. Most libraries do not perform an immediate return of investment. In addition, it is not convenient to compare a large-scale library (national library) with a small library (school library). In this sense, it is not recommended to waste resources or energy in this subject.

If the market cannot be analyzed, it does not exist at all. Challenges imposed by the disruptive technological innovation provokes that every library designs a medium- and long-term plan. The explicit intention is to have an optimal use of the new technology and foresee its possible defects. However, the experience confirms that a number of libraries waste few resources in the elaboration of these plans, circumstances that interfere in the implementation and use of new technologies.

Libraries are capable to detect their problems. This is achieved once the change in the organizational culture is produced as a direct consequence of the disruptive technological innovation. The organizational values must be settled in the modifications made to the individual values.

Technological transfer does not equal market demand. This fifth principle represents two practical problems for librarians. First, the absence of clear data on products and services due to the scarce investment in those researches. Second, ignorance on their cost since users do not pay for these. By lacking estimates on the permanence time, products or services, administrators cannot estimate an actual value to their market demands.

The acceptance or reluctance of the culture imposed by disruptive technological innovation may be used as a basis from where several authors expose their points of view about the way it determines, in a lesser or greater extent, the organization of information and knowledge. From a manager's viewpoint, Glushko [9] indicates that the organization is defined as a system that intentionally displays collections of resources and how their supports interact. BL knowledge should include subject of library and information science, computer science, system analysis and others disciplines.

The issue is that BL must not be feared to reformulate those existing knowledge organization systems [11]. On the other hand, Wah and Choh [10] considered that new knowledge situated in the globalized world (userfocused model) demands greater effort than knowledge directed to products and services. The user-focused model entails the use of technological platforms where several contents are offered and communication media as well as multiple channels are used.

Unfortunately, if librarians still think in organizing physical objects by different shapes and formats, relegating digital information analysis, the organization system will take longer to be modified, getting left behind of every new event in the digital environment. Platforms manifest the way in which disruptive technological innovation breaks through the barrier of access to the library and its collections. It opens the possibility of creating services that connect people with knowledge along with digital content managers. These professionals capture, organize, store and recover digital information while combining the traditional functions of library practices, of final user service and with external communities, or functions of theme experts.

Innovation culture in information organization demands to the BL those skills to take transdisciplinary pathway through new horizons during the coexistence and transition period among analog and digital systems.

\subsection{The BL and His/Her Challenges in Digital Information Retrieval}

In 1950, Calvin Mooers [12] defined information retrieval as the process or method by which a user is able to turn his/her information need in a list of useful documents within the universe of stored documents. Separating from this concept, Mooers established a law for information retrieval systems, which indicated that an information retrieval system will tend not to be used whenever it is more painful and troublesome to have information than not to have it. This law is directed to an efficient information retrieval, that is, it corresponds with the notions of significance and relevance.

Recovering significant and relevant digital information is one of the BL challenges. More so, since methods for organization and retrieval of printed information have already been validated, even though, these methods should be improved. Some situations in digital information retrieval have no referent in the print world, consequently demanding different analysis processes and representation models. The immediate challenges that the BL should confront regarding information retrieval are the following:

1) Information retrieval in the environment of the Internet of Things. The Internet of Things (IoT) is a term proposed by Kevin Ashton in 1999 during a presentation where he argued that associating physical objects with RFID [13] labels could provide an identity for every object, generating data on such things. The novelty was that 
until that moment, available information in the Internet was produced almost exclusively by individuals or computarized systems (such as flight information), not by physical things. The IoT is defined as the time in which more "things or objects" are connected to the Internet than people.

These devices belong to SmartThings technology, physical objects that gather and transmit information more or less in an autonomous way [14]. However, even if that means we already have smartphones, they actually are not smart yet. Baris Gultekin, who developed Google Now, indicates that SmartThings will work for us and provide information without us asking for it [15].

In this sense, the challenge is to find adequate standards to recover much more information of diverse nature, which will strongly lead towards data management. It appears that before the Internet of Things and the installation of a hyperconnected global society, information and data had already surpassed us. Suffice it to say that in the Internet's sea of information, Library and Information Science professionals have not explored some layers, but they do exist and are used by some people, like the Deep web.

2) Retrieval in the Deep Web. As it is well known, the surface web is a network of billions of linked HTML websites. Traditionally, search engines track the Internet to locate and recover data. Deep web or Darknet refers to web contents which may not be accessed by traditional search engines [16]. The Deep web is a big and unregulated place. Despite its great amount of information, it continues to be an unexplored part of the digital world. Many Internet users have not even heard of it and have the impression that results from Google search engines is everything the Web has to offer. However, these situations have to be considered and confronted with alternatives which may be proposed by librarians.

3) Big data. Boyd [17] conceptualizes Big Data as a cultural, technological and academic phenomenon supported by the interaction among these elements:

a) Technology: maximization of calculation power and algorithmic accuracy to gather, analyze, link, and compare big data groups.

b) Analysis: based on big data groups to identify patterns of social, economic, technical, and legal demands.

c) Myths: the generalized belief that big data groups offer a superior form of intelligence and knowledge that were impossible ideas before, with an aura of truth, objectivity, and accuracy. Big Data is not a scenario where numbers speak for themselves, but they require an interpretation.

Big Data is perceived as a far-reaching tool to face several social issues. Its retrieval and interpretation offers the potential of new understanding in areas as different as medicine and security, among others.

Since data are heterogeneous, these should be structured before their analysis. A challenge for the librarian is to create metadata to describe recorded data, for instance, in scientific experiments. Metadata will help to create what is called data origin, which will facilitate the identification of the location where first data was originated and the relations with subsequent data. Data origin will help to create a follow-up to validate and analyze these.

As data grow in volume, filtration techniques and real-time recording of stored data are urgently needed, since accumulating all data and performing a later analysis is not possible. This is another challenge the librarian must face regarding information retrieval, although there are several concerning information access [18].

\subsection{The Blended Librarian and His/Her Challenges in Information Services}

Web 2.0 technology produced a provisional environment for library and information services called blended environment. Buckland [19] established that every technological innovation has a significant effect in library services, so the Web 2.0 would not be an exception. This Web 2.0 setting seeks to combine reference work with activities that involve the creation, management, and assessment of information, tools and services, including as well research on information resources.

Organization and retrieval services in libraries or other information units want to have access and immediately use external data, from publishers, contents intermediaries, etc., by means of "references transactions". The Reference and User Services Association (RUSA) [20] defines these as information consultations in which library staff recommend, interpret, evaluate and/or use information resources to help their users to meet particular information needs.

This transaction is an information contact that involves the knowledge, use, recommendation, interpretation, or instruction in the use of one or more information sources by a member of the library staff. Its components are the following:

1) Information and referral service 
2) Information resources: printed and non printed material; databases; the library's own catalogs and other holding records; other libraries and institutions through communications or referrals

Moreover, Buckland encourages librarians to redefine their strategies in a setting that demands to be competent in ICTs. Not for nothing, recently the para-academic role of the librarian and his/her participation as a facilitator in open learning supported by online resources have become relevant. An information network setting requires that the blended librarian includes new technological aptitudes into his/her formal knowledge.

Wijnhoven [21] establishes that "information services should facilitate the exchange of these information goods through time and space, with or without transforming them", a statement which we agree with.

An essential task of the blended librarian is to provide printed or digital information goods with semantic meaningful contents. Results should always be in accordance with the different scenarios and with the librarian's competence in reference work. Heading to socialize library services, the expert has to:

1) Plan and identify users and needs: Project the supply of information resources, staff training, and users guidance. Spread the news about the benefits of creating social networks for the community's information and knowledge. Establish guidelines, standards and quality indicators.

2) Ensure the fulfillment of contract, legal and ethical obligations: Promote good practices.

3) Implement the integration of social networks, applications and Web 2.0 tools in their institution website: These instruments are useful for the promotion of library services through platforms and in the organization and exchange of contents (youtube, iTunes, Twitter, Facebook).

4) Monitor the statistics of online reference consultations [22].

Librarians and Library and Information Science professionals have become facilitators of user experiences. Nowadays, people require and use information at any moment and in every place, so libraries have the opportunity to go back being centers of academic and scientific activity. Reaching those goals in a medium term, demands that universities and institutions specialized on Library and Information Science provide their students with a solid traditional education in the discipline and reinforce knowledge, but specially the application of disruptive technological innovations. Academic programs with subjects related to library software management, Bibliometrics, or marketing are a necessity for active and experienced librarians as well as for recently graduated students or those who are almost there.

New users or Web 2.0 users represent an enormous challenge for the librarian because, as Godwin refers, they normalize and simplify access to technology and information by doing the following:

- Their use of online information and technology appears natural and effortless.

- They expect to find single searches.

- They find library databases too difficult. They have no interest in learning about Boolean logic.

- They like collaboration, teamwork and social networking.

- They navigate the web with a trial and error "compass". They ignore manuals and help-sheets.

- Their research is self-directed, and likely to be non linear since they are hypertext thinkers.

- Multitasking is their way of life, they live in a state of continuous partial attention.

- They think what is written down on the web must be correct.

- They work with micro content: single song, photos and blogpost. They are either confused or ignorant about ethical issues around the content they are using.

- They will cut and paste rather then read and digest what they find in the Internet.

- They need databases to be in a Virtual Learning Environment (VLE).

The meeting point of three spheres: information, people and technology, are the blended library functions, ergo, the occupations of the blended librarian [23].

Even though everything seems to indicate that the arrival of the Web 2.0 volatilizes the formats and functions of libraries and librarians with disruptive technological mechanisms, such as content systems (wikis, forums, blogs), synchronous and asynchronous communication instruments (RSS, Messenger, Skype), tagging and mashups, all of them originated in the document retrieval model [24].

These recent information retrieval models require blended librarians. Corral [25] establishes three categories and provides examples:

1) e-content and digital library specialists (content + conduit): electronic resources co-ordinators; digital collection project managers; directors of digital libraries; heads of e-strategy, intranet/web managers and repository librarians;

2) discipline-based information and knowledge specialists (content + context + conduit): subject/liaison li- 
brarians, information literacy co-ordinators; instructional design librarians; geographic information systems specialists; data librarians; data scientists; and

3) context-specific technology and media specialists (context + conduit): computer-assisted learning specialists; educational/instructional/learning technologists.

\section{Conclusions}

In the current digital sea of information, users tend to navigate the Internet for too much time to recover information, contrary to Mooers' Law. Here, the librarian has to adopt a less passive role and develop more efficient information retrieval systems, which are able to confront with the boundless abundance of data and information contents in digital media.

In order to develop such systems, the blended librarian appears as an expert with solid theoretical basis in information representation and organization, besides their knowledge of functional aspects in several areas, such as computer science. This field aids blended librarians in the management of technological tools to design additional products and services for conventional libraries.

In this paper, the notion of blended librarian is preferred rather than disruptive librarian, given that disruptive qualifies what is totally new and blended librarian combines knowledge of different nature to completely carry out his/her role in a scenario of constant technological change.

The new roles and responsibilities of blended librarians are outlined towards a professional who knows how to precede and coexist with the always changing disruptive technological innovation. Active learning based on research and collaboration among peers are the ingredients of this informational landscape constantly eroded by innovative information dynamics.

\section{Acknowledgements}

Jenny Teresita Guerra González thanks the Postdoctoral Fellowship Program at UNAM for their support.

\section{References}

[1] Jain, R.K., Triandis, H.C. and Weick, C.W. (2010) Managing Research, Development, and Innovation: Managing the Unmanageable. John Wiley, New Jersey, 249, 324. http://dx.doi.org/10.1002/9780470917275

[2] Chesbrough, H. (2010) Business Model Innovation: Opportunities and Barriers. Long Range Planning, 43, $354-363$. http://dx.doi.org/10.1016/j.lrp.2009.07.010

[3] Higa, M. (2005) Redesigning a Library’s Organizational Structure. http://crl.acrl.org/content/66/1/41.full.pdf

[4] Brower, M. (2011) A Recent History of Embedded Librarianship: Collaboration and Partnership Building with Academics in Learning and Research Environments. In: Kvenild, C. and Calkins, K., Eds., Embedded Librarians: Moving Beyond One-Shot Instruction, Association of College and Research Libraries, Chicago, 3-16.

[5] Bell, J. and Shank, J. (2014) The Blended Librarian. A Blueprint for the Reading the Teaching of Learning Role of Academic Librarians. College and Research Libraries New, 373.

[6] Ryszard Kruk, S. (2009) Semantic Digital Libraries. Springer, Berlin, 71-76. http://dx.doi.org/10.1007/978-3-540-85434-0 5

[7] Nielsen, J. (2013) The Blended Business Librarian: Technology Skills in Academic Business Librarian Job Advertisements. Journal of Business \& Finance Librarianship, 18, 119-128. http://dx.doi.org/10.1080/08963568.2013.768849

[8] Christensen, C. (1997) The Innovator’s Dilemma. Harvard Business School, Boston.

[9] Glushko, R. (2013) The Discipline of Organizing. MIT Press, Massachussets.

[10] Wah, C. and Choh, N. (2008) Back to the Future: Augmenting Competencies for Library 2.0. Singapore Journal of Library Management, 37.

[11] Abbas, J. (2010) Structures for Organizing Knowledge. Explaining Taxonomies, Ontologies and Other Schemas. Neal Schuman, New York.

[12] Mooers, C. (1951) Making Information Retrieval Pay. Zator Company, Michigan.

[13] Hunt, V.D. (2007) RFID: A Guide to Radio Frequency Identification. Wiley-Interscience, New York. http://dx.doi.org/10.1002/0470112255

[14] Evans, D. (2014) The Internet of Things. How the Next Evolution of the Internet Is Changing Everything Internet. http://www.cisco.com/web/about/ac79/docs/innov/IoT_IBSG_0411FINAL.pdf 
[15] Mark, H. (2014) Battle of the Digital Assistants: Cortana, Siri, and Google Now. PC World, 13.

[16] Bloem, J. (2013) Things-Internet of Business Opportunities, VINT Research Report. http://www.ict-books.com/books/inspiration-trends/inspiration-trends/vint-report-things1-en-detail

[17] Boyd, D. (2012) Critical Questions for Big Data. Information, Communication \& Society, 15, 662-679. http://dx.doi.org/10.1080/1369118X.2012.678878

[18] Saint, A. (2015) Where Next for the Internet of Things? Engineering \& Technology, 10, 72-75. http://dx.doi.org/10.1049/et.2015.0111

[19] Buckland, M. (1992) Redesigning Library Services: A Manifesto. American Library Association, Chicago.

[20] Reference and User Services Association (RUSA) (2015) http://www.ala.org/rusa/

[21] Wijnhoven, F. (2012) Information Services Design. A Design Science Approach for Sustainable Knowledge. Routledge, New York.

[22] Baeza-Yates, R. and Ribeiro-Neto, B. (2011) Modern Information Retrieval. The Concepts and Technology behind Search. Pearson, London.

[23] Department of Library \& Information Sciences/University of North Texas (2015) https://lis.unt.edu/BSIS

[24] Huvila, I., Holmberg, K., Kronqvist-Berg, M., Nivakoski, O. and Widén, G. (2013) What Is Librarian 2.0? New Competences or Interactive Relations? A Library Professional Viewpoint. Journal of Librarianship and Information Science, 45, 198-205. http://dx.doi.org/10.1177/0961000613477122

[25] Corral, S. (2010) Educating the Academic Librarian as a Blended Professional: A Review and Case Study. Library Managment, 31, 567-593. http://dx.doi.org/10.1108/01435121011093360 